Bài báo khoa học

\title{
Nghiên cứu đặc điểm một số chất dinh dưỡng trong môi trường nước biển ven bờ khu vực phía Nam châu thổ sông Hồng
}

\author{
Lưu Việt Dũng ${ }^{1,2^{*}}$, Nguyễn Tài Tuệî, ${ }^{2,1}$ Phạm Văn Hiếu ${ }^{3}$, Nguyễn Doanh Khoa ${ }^{1}$, Lê Văn \\ Dũng ${ }^{1}$ \\ ${ }^{1}$ Phòng thí nghiệm trọng điểm Địa môi trường và Ứng phó biến đổi khí hậu, Trường Đại \\ học Khoa học Tự nhiên, Đại học Quốc gia Hà Nội; dungluuviet@gmail.com; \\ tuenguyentai@hus.edu.vn; khoa.k59ktdc@gmail.com; \\ levandung.qltnmtkhtn@gmail.com \\ ${ }^{2}$ Khoa Địa chất, Trường Đại học Khoa học Tự nhiên, Đại học Quốc gia Hà Nội; \\ dungluuviet@gmail.com; tuenguyentai@hus.edu.vn; khoa.k59ktdc@gmail.com; \\ levandung.qltnmtkhtn@gmail.com \\ ${ }^{3}$ Viện Nghiên cứu Biển và Hải đảo, Tổng cục Biển và Hải đảo Việt Nam; \\ hieupv.env@gmail.com \\ *Tác giả liên hệ: dungluuviet@gmail.com; Tel.: +84-904729009
}

Ban Biên tập nhận bài: 12/9/2021; Ngày phản biện xong: 15/10/2021; Ngày đăng bài: $25 / 1 / 2022$

Tóm tắt: Các chất dinh dưỡng trong môi trường nước biển vùng bờ có vai trò hết sức quan trọng đối với các hệ sinh thái và các loài sinh vật vùng bờ nhưng sự gia tăng hàm lượng của các chất dinh dưỡng này cũng gây tác động tiêu cực lên các hệ sinh thái kể trên. Trong phạm vi của nghiên cứu này, hàm lượng của các chất dinh dưỡng gồm Amoni, Nitrate và Phosphate và các thông số hóa lý cơ bản trong môi trường nước biển vùng bờ tại khu vực phía nam Châu thổ sông Hồng đã được phân tích và đánh giá tại vùng cửa sông, rừng ngập mặn và vùng biển ven bờ. Kết quả nghiên cứu cho thấy giá trị hàm lượng Nitrate có sự khác biệt rõ rệt giữa các khu vực lấy mẫu dao động từ $119 \pm 50,7 \mu \mathrm{g} / \mathrm{L}, 192,3 \pm 47,5 \mu \mathrm{g} / \mathrm{L}$ đến $454,8 \pm 204,1 \mu \mathrm{g} / \mathrm{L}$ tương ứng với vùng biển ven bờ, rừng ngập mặn và cửa sông. Kết quả tương tự cũng được quan sát thấy với Amoni với hàm lượng tương ứng là $835,3 \pm 246,4$ $\mu \mathrm{g} / \mathrm{L}, 405,7 \pm 126,7 \mu \mathrm{g} / \mathrm{L}$, và $295,6 \pm 73,2 \mu \mathrm{g} / \mathrm{L}$ tương ứng với vùng cửa sông, rừng ngập mặn và vùng biển ven bờ. Các chất dinh dưỡng như Amoni và Nitrate đã vượt quá giới hạn cho phép theo QCVN 10-MT:2015/BTNMT và tiêu chuẩn môi trường ASEAN đối với môi trường nước biển ven bờ cho mục đích nuôi trồng thủy sản và bảo tồn thủy sinh. Nghiên cứu cũng chỉ ra vai trò của rừng ngập mặn trong việc hấp thu các chất dinh dưỡng được vận chuyển từ lục địa ra vùng ven biển và cần tiếp tục thực hiện các nghiên cứu liên tục trong thời gian tới nhằm làm rõ vấn đề này.

Từ khóa: Rừng ngập mặn; Cửa sông; Vùng bờ; Dinh dưỡng; Châu thổ sông Hồng.

\section{Mở đầu}

Vùng bờ là nơi tập trung nhiều hoạt động kinh tế quan trọng như công nghiệp, cảng biển, nuôi trồng thủy sản (NTTS), du lịch,... nhưng cũng là nơi tiếp nhận các nguồn ô nhiễm từ đất liền, có nguy cơ cao về ô nhiễm môi trường và mức độ tổn thương từ biến đổi khí hậu [1]. Một trong những nguồn gây ô nhiễm vận chuyển từ đất liền ra vùng cửa sông, ven biển là các chất dinh dưỡng như $\mathrm{N}, \mathrm{P}, \mathrm{Si}$ có thể gây ra tác động đến môi trường biển ven bờ như phú 
dưỡng, hình thành vùng môi trường chết (hypoxia), tác động trực tiếp đến các hệ sinh thái (HST) và đa dạng sinh học [2-4]. Các nguồn ô nhiễm các chất dinh dưỡng ảnh hưởng đến môi trường biển bao gồm: các nhà máy, khu đô thị đô thị, sản xuất nông nghiệp, chất thải sinh hoạt, nuôi trồng thủy sản ven biển. Sự gia tăng hàm lượng Phospho có nguồn gốc từ lục địa có thể gây ra suy giảm chất lượng môi trường nước, trầm tích và đa dạng sinh học trong khu vực rừng ngập mặn tại Brazil và Ấn Độ $[2,5,6]$. Tuy nhiên, sự gia tăng nồng độ các chất dinh dưỡng cũng thể hiện tác động tích cực như làm gia tăng và phát triển của hệ sinh thái rừng ngập mặn [7], nâng cao tốc độ sinh trưởng, sinh khối của rừng ngập mặn theo thời gian [8]. Các chất dinh dưỡng này cũng có vai trò quan trọng đối với sự phát triển của ác loài thực vật phù du, góp phần duy trì lưới thức ăn tại các HST ven biển.

Như vậy, có thể nhận thấy các nguồn dinh dưỡng từ lục địa có các vai trò khác nhau đối với các hệ sinh thái biển như rừng ngập mặn, vùng nước cửa sông và các bãi triều ven biển. Nghiên cứu về tải lượng chất dinh dưỡng tại sông Hồng cho thấy các hoạt động tưới tiêu nông nghiệp và thất thoát từ môi trường đất là nguyên nhân chính dẫn đến gia tăng hàm lượng $\mathrm{N}, \mathrm{P}$ trong nguồn nước sông Hồng [9]. Các nghiên cứu gần đây cũng chỉ ra hàm lượng chất dinh dưỡng N, P, Si trong nước sông Hồng đã dần đến điểm giới hạn xảy ra phú dưỡng trong giai đoạn hiện nay [10]. Vì vậy, việc nghiên cứu và đánh giá được vai trò và tác động của các chất dinh dưỡng tại khu vực châu thổ sông Hồng hiện nay cũng là vấn đề cần được quan tâm nhằm bảo vệ các HST và đa dạng sinh học trong thời gian tới. Trong phạm vi của nghiên cứu này, hàm lượng các chất dinh dưỡng gồm Amoni, Nitrate, Phosphate và các thông số hóa lý trong môi trường nước biển được thu thập và phân tích tại khu vực cửa sông, rừng ngập mặn và ven bờ nhằm đánh giá được mức độ tích lũy các chất dinh dưỡng và nguy cơ ảnh hưởng đến môi trường và các hệ sinh thái trong khu vực phía nam châu thồ sông Hồng.

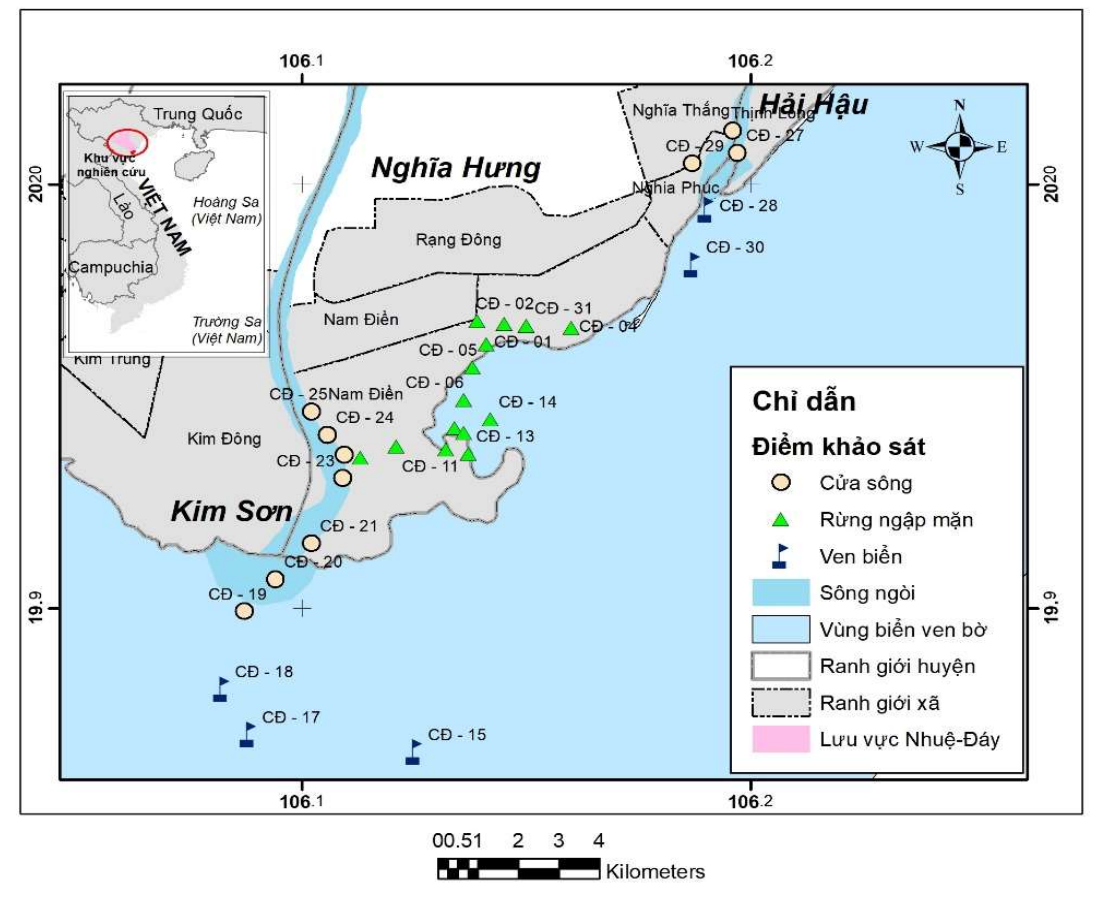

Hình 1. Khu vực nghiên cứu và điểm lấy mẫu tại khu vực phía Nam châu thổ sông Hồng.

\section{Phương pháp nghiên cứu}

\subsection{Khu vưc nghiên cúu}

Nghiên cứu được thực hiện tại khu vực ven biển nằm phía Nam châu thổ sông Hồng (thuộc khu dự trữ sinh quyển cửa sông Hồng), giới hạn bởi khu vực cửa sông Đáy và cửa 
sông Ninh Cơ. Đây là khu vực tập trung nhiều hoạt động phát triển kinh tế xã hội ven biển như nuôi trồng và đánh bắt thủy hải sản, nông nghiệp nhưng ít phát triển hoạt động công nghiệp, cảng biển. Tuy nhiên, khu vực này còn chịu ảnh hưởng bởi nguồn chất thải từ lưu vực sông Nhuệ-Đáy được vận chuyển từ cửa sông Đáy ra vùng biển khu vực châu thổ Sông Hồng. Khu vực này còn tập trung các hệ sinh thái đất ngập nước quan trọng như rừng ngập mặn, vùng nước cửa sông, bãi triều ven biển,.. có vai trò quan trọng đối với duy trì sinh kế của cộng đồng địa phương và cung cấp nguồn lợi thủy hải sản giá trị. Sơ đồ khu vực nghiên cứu được thể hiện trong Hình 1.

\subsection{Khảo sát thực địa và lấy mẫu}

Các mẫu nước biển ven bờ được thu thập và khảo sát tại 03 khu vực cửa sông, rừng ngập mặn và ven bờ tại khu vực phía. Mẫu nước biển ven bờ tầng mặt được thu thập 01 lần khi triều cao vào tháng $01 / 2020$ bao gồm 05 mẫu nước tại vùng biển ven bờ, 14 mẫu nước tại các khu vực rừng ngập mặn và 10 mẫu nước tại cửa sông (Hình 1). Vị trí lấy mẫu được thực hiện kéo dài từ khu vực cửa sông Ninh Cơ đến cửa sông Đáy thuộc khu vực phía Nam châu thổ sông Hồng. Mẫu nước thu thập được chứa trong chai nhựa PE nguyên sinh, bảo quản ngay trong thùng đá và vận chuyển về phòng thí nghiệm trước khi tiến hành phân tích thành phần các chất dinh dưỡng. Các thông số hiện trường được tiến hành đo đạc trực tiếp tại hiện trường sau khi thu thập mẫu.

\subsection{Phưong pháp xác định thành phần chất dinh dữ̛ng trong môi trương nước biển}

\subsubsection{Phương pháp xác định các thông số hóa lý môi trường}

Các thông số hóa lý môi trường nước biển ven bờ bao gồm pH, TDS, Eh, Độ muối được đo đạc trực tiếp tại hiện trường bằng hệ thống đo nhanh đa chỉ tiêu Horiba WQC 30 với các điện cực kỹ thuật số 300-PH2 cho pH, 300-C2 cho độ muối và TDS, điện cực thủy tinh 9300$10 \mathrm{D}$ cho giá trị thế ôxy hóa khử Eh. Sai số của thiết bị trong quá trình đo đạc hiện trường là không quá $0,5 \%$ đối với điện cực kỹ thuật số và $0,1 \mathrm{mV}$ đối với điện cực thủy tinh.

\subsubsection{Phương pháp phân tích Amoni, Nitrate va Phosphat trong môi trường nước biển}

Hàm lượng Amoni, Nitrate và Phosphat trong môi trường nước biển được phân tích bằng hệ thống phân tích tự động dòng liên tục CFA Skalar SAN++ (Skalar Analytical BV, Breda, The Netherlands) tại Phòng thí nghiệm trọng điểm Địa môi trường và Úng phó Biến đổi Khí hậu, Khoa Địa chất, Trường Đại học Khoa học Tự nhiên. Trước khi tiến hành phân tích, mẫu nước được lọc qua giấy lọc định lượng nhằm loại bỏ các vật chất lơ lửng có kích thước lớn hơn $10 \mu \mathrm{m}$. Mẫu nước biển ven bờ sau khi lọc được giữ trong thùng đá và được phân tích ngay trong ngày lọc mẫu.

Quá trình phân tích tự động Amoni $\left(\mathrm{NH}_{4}-\mathrm{N}\right)$ được dựa trên phản ứng Berthelot, trong đó Amoni được clo hóa thành monocloramin và được cho phản ứng với phenol. Trong quá trình phản ứng, Natri nitroprusside và Natri hypoclorit được sử dụng là chất xúc tác cho phản ứng. Sản phẩm phản ứng tạo thành phức chất màu xanh lục và được đo đạc bằng đầu dò quang học với bước sóng $630 \mathrm{~nm}$. Đối với mẫu có hàm lượng Amoni dự kiến cao hơn 500 $\mu \mathrm{g} / \mathrm{L}$ sẽ được pha loãng ít nhất 2 lần trước khi tiến hành phân tích. Nguyên lý của phân tích Nitrate $\left(\mathrm{NO}_{3}-\mathrm{N}\right)$ trong môi trường nước biển sử dụng phương pháp khử Cadimi; mẫu phân tích được tự động đưa cùng dung dịch đệm $\mathrm{pH}$ 8,2 quá cột chứa cadimi phủ đồng để khử Nitrate trong nước biển thành Nitrite. Nitrite sau phản ứng được xác định bằng cách diazo hóa với Sulfanilamide và kết hợp với $\mathrm{N}-(1-$ naphthyl) Ethylene diamine dihydrochloride để tạo thành màu hồng và được đo ở bước sóng 540nm. Hàm lượng Phosphat $\left(\mathrm{PO}_{4}-\mathrm{P}\right)$ trong nước biển được xác định bằng phàn ứng giữa Amoni heptamolybdate và Kali antimony (III) oxide tartrate trong môi trường axit vừa với dung dịch chứa phosphate để tạo phức Amoni- 
Phospho-Molybdate. Phức chất này trong quá trình khử có mày xanh lam đậm khi phản ứng với $\mathrm{L}(+)-$ Ascorbic axit và được đo ở bước sóng $880 \mathrm{~nm}$. Các modul phản ứng và lấy mẫu được vận hành tự động thông qua hệ thống $\mathrm{CFA} \mathrm{SAN}++$ và phần mềm điều khiển FlowAccess V3 của hãng Skalar [11].

\subsubsection{Kiểm soát chất lượng phân tích}

Trong quá trình thực hiện phân tích, việc kiểm soát chất lượng phân tích được thực hiện theo hướng dẫn của hãng Skalar và thực hiện phân tích mẫu lặp trong quá trình phân tích [11]. Các hóa chất chuẩn phục vụ phân tích được sử dụng xây dựng đường chuẩn và kiểm tra chất lượng phân tích bao gồm Natri nitrate (Merck 106537), Amoni Clorua (Merck 101145) và Kali Dihydro phosphate (Merck104873). Giới hạn phát hiện của phép phân tích có thể đạt được đối với Nitrate và Amonium là $5 \mu \mathrm{g} / \mathrm{l}$ và Phosphate là $2 \mu \mathrm{g} / \mathrm{l}$. Sau 10 mẫu phân tích, một mẫu chất chuẩn được lặp lại nhằm hiệu chỉnh sự biến đổi tín hiệu (nếu có) của đầu dò trong quá trình phân tích. Việc hiệu chuẩn kết quả phân tích này được thực hiện tự động trong phần mềm FlowAccesss V3. Các mẫu lặp của chất chuẩn và mẫu phân tích được đánh giá nhằm đảm bảo mức độ sai khác giữa các lần phân tích không quá $5 \%$, giá trị $\mathrm{R}$ của đường chuẩn phân tích trong khoảng 0,99 đến 0,999 .

\subsection{Phwơng pháp xủ lý số liệu}

Kết quả phân tích mẫu được xử lý bằng phần mềm FlowAccess V3 và xuất dữ liệu phân tích ra Microsoft Excel. Kết quả phân tích được xử lý thống kê bằng phần mềm SPSS và các biểu đồ được thực hiện bằng phần mềm Sigmaplot. Nhằm đánh giá sự khác biệt về các thông số hóa lý môi trường và hàm lượng các chất dinh dưỡng giữa các khu vực vùng biển ven bờ, cửa sông và rừng ngập mặn, phép thống kê phân tích phương sai (ANOVA) và phân tích tương quan được thực hiện bằng phần mềm SPSS. Sự khác biệt có ý nghĩa thống kê giữa các khu vực lấy mẫu được ghi nhận nếu giá trị $\mathrm{p}<0,05$.

\section{Kết quả và Thảo luận}

\section{1. Đặc điểm các thông số hóa lý môi trương nước tại khu vục nghiên cưu}

Đặc điểm các thông số hóa lý môi trường nước biển tại khu vực nghiên cứu gồm $\mathrm{pH}, \mathrm{Eh}$, TDS và độ muối (Sal) được thể hiện trong Hình 2. Kết quả nghiên cứu cho thấy giá trị pH dao động từ 7,5 đến 8,6 và không thấy có giá trị khác biệt giữa các khu vực lấy mẫu. Giá trị $\mathrm{pH}$ trung bình $( \pm \mathrm{SD})$ của từng khu vưc là $8,3 \pm 0,1,8,3 \pm 0,1$ đến $8,1 \pm 0,3$ với mẫu nước biển ven bờ, cửa sông và rừng ngập mặn (Hình 2$)$. Tương tự như $\mathrm{pH}$, giá trị Eh cũng không cho thấy sự khác biệt giữa các khu vực lấy mẫu với khoảng dao động từ 121,9 đến 189,2 mV, giá trị trung bình tương ứng là $143,1 \pm 15,4 \mathrm{mV}, 149,4 \pm 24,4 \mathrm{mV}$, và $150,3 \pm 16,4 \mathrm{mV}$ cho mẫu nước biển ven bờ, cửa sông và rừng ngập mặn. Giá trị $\mathrm{pH}$ và Eh tại khu vực nghiên cứu có mức độ tương quan nghịch trung bình (Bảng 1$)$. Từ kết quả giá trị $\mathrm{pH}$ và Eh cho thấy khu vực nghiên cứu nằm trong nhóm môi trường kiềm yếu-oxy hóa yếu $(7,5<\mathrm{pH}<8,5 ; 100 \mathrm{mV}$ $<\mathrm{Eh}<150 \mathrm{mV})$ và môi trường kiểm yếu - oxy hóa mạnh $(7,5<\mathrm{pH}<8,5 ; \mathrm{Eh}>150 \mathrm{mV})$.

Đặc điểm độ muối dao động từ 11,7 đến $29,3 \%$ và có sự khác biệt rõ ràng giữa khu vực cửa sông và rừng ngập mặn với nước biển ven bờ (ANOVA, $\mathrm{F}=4,237, \mathrm{p}<0,05)$. Giá trị trung bình $( \pm \mathrm{SD})$ của độ muối tương ứng là $22,4 \pm 2,5 \%$, $22,4 \pm 4,1 \%$ và $26,8 \pm 1,8 \%$ o cho khu vực rừng ngập mặn, cửa sông và nước biển ven bờ (Hình 2). Xu thế tương ứng cũng diễn ra với TDS khi hàm lượng TDS trong nước biển tại khu vực nghiên cứu dao động từ 11,3 đến $28,2 \mathrm{~g} / \mathrm{L}$, giá trị trung bình $( \pm \mathrm{SD})$ là $21,6 \pm 2,4,21,6 \pm 4,0$ và $25,8 \pm 1,7 \mathrm{~g} / \mathrm{L}$ cho khu vực rừng ngập mặn, cửa sông và nước biển ven bờ (Hình 2).

Nhìn chung, giá trị độ muối và TDS thể hiện xu thế phù hợp với nước biển tại các vùng cửa sông và rừng ngập mặn với giá trị độ muối biến thiên lớn và có liên quan trực tiếp đến 
nguồn nước ngọt từ lục địa chảy ra biển. Đặc điểm các thông số môi trường tại khu vực nghiên cứu đều có giá trị tương đương với các khu vực cửa sông khác tại Việt Nam và không thể hiện các dấu hiệu bất thường về đặc điểm môi trường [12-13]. Tuy nhiên, đặc điểm các thông số về môi trường nước biển ven bờ và cửa sông có sự biến động theo mùa [13-14] nên việc tiến hành các nghiên cứu tiếp theo nhằm đánh giá biến động đặc điểm môi trường theo thời gian tại khu vực này là rất cần thiết trong các nghiên cứu tiếp theo.


Hình 2. Đặc điểm các thông số hóa lý môi trường nước biển vùng bờ khu vực nghiên cứu.

Ghi chú: CS: Cửa sông; NBVB: Nước biển ven bờ; RNM: Rùng ngập mặn

Bảng 1. Hệ số tương quan giữa các thông số hóa lý môi trường và hàm lượng các chất dinh dưỡng trong môi trường nước biển.

\begin{tabular}{|c|c|c|c|c|c|c|c|}
\hline & pH & Eh & TDS & Độ muối & $\mathrm{PO}_{4}-\mathrm{P}$ & $\mathrm{NO}_{3}-\mathrm{N}$ & $\mathrm{NH}_{4}-\mathrm{N}$ \\
\hline $\mathrm{pH}$ & & $-0.455^{*}$ & & & & & \\
\hline $\mathrm{Eh}$ & $-0.455^{*}$ & & & & & & \\
\hline TDS & & & & $0.999^{* *}$ & $-0.475^{* *}$ & $-0.399^{*}$ & $-0.370^{*}$ \\
\hline Độ muối & & & $0.999^{* *}$ & & $-0.473^{* *}$ & $-0.390^{*}$ & \\
\hline $\mathrm{PO}_{4}-\mathrm{P}$ & & & $-0.475^{* *}$ & $-0.473^{* *}$ & & $0.485^{* *}$ & $0.499^{* *}$ \\
\hline $\mathrm{NO}_{3}-\mathrm{N}$ & & & $-0.399^{*}$ & $-0.390^{*}$ & $0.485^{* *}$ & & $0.953^{* *}$ \\
\hline $\mathrm{NH}_{4}-\mathrm{N}$ & & & $-0.370^{*}$ & & $0.499^{* *}$ & $0.953^{* *}$ & \\
\hline
\end{tabular}

* Hệ số tương quan với giá trị $\mathrm{p}<0,05 ;$ ** Hệ số tương quan với giá trị $\mathrm{p}<0,001$

3.2. Đặc điểm phân bố các chất dinh dương trong môi trương nước biển vùng bờ khu vực nghiên cưu

Kết quả nghiên cứu cho thấy giá trị hàm lượng $\mathrm{NO}_{3}-\mathrm{N}$ trong môi trường nước biển vùng bờ tại khu vực nghiên cứu dao động từ 80 đến $853,1 \mu \mathrm{g} / \mathrm{L}$ với giá trị trung bình $( \pm \mathrm{SD})$ là $270,2 \pm 184,6 \mu \mathrm{g} / \mathrm{L}$. Giá trị trung bình hàm lượng $\mathrm{NO}_{3}-\mathrm{N}$ trong môi trường nước biển ven bờ tương ứng là $119 \pm 50,7 \mu \mathrm{g} / \mathrm{L}, 192,3 \pm 47,5 \mu \mathrm{g} / \mathrm{L}$ đến $454,8 \pm 204,1 \mu \mathrm{g} / \mathrm{L}$ với vùng biển ven bờ, rừng ngập mặn và cửa sông (Hình 3 ). Kết quả phân tích cũng cho thấy giá trị $\mathrm{NO}_{3}-\mathrm{N}$ có sự 
khác biệt có ý nghĩa thống kê giữa các khu vực (ANOVA, $\mathrm{F}=16.945, \mathrm{p}<0,001)$ và thể hiện xu hướng giảm dần từ cửa sông tới rừng ngập mặn và nước biển ven bờ.
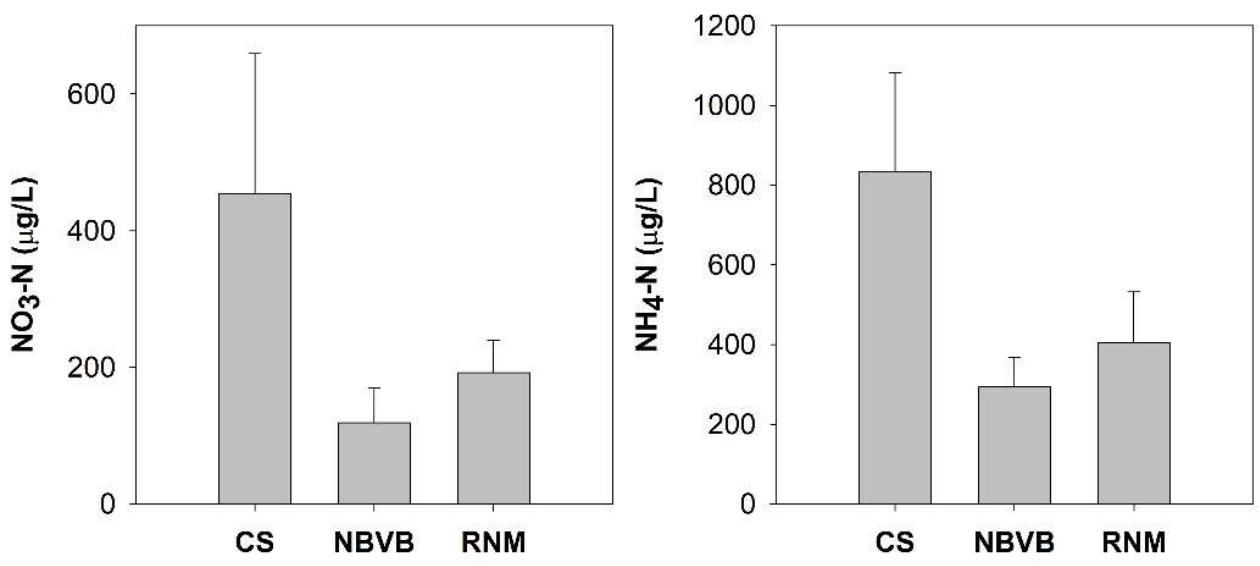

Hình 3. Đặc điểm phân bố hàm lượng $\mathrm{NO}_{3}-\mathrm{N}$ và $\mathrm{NH}_{4}-\mathrm{N}$ trong môi trường nước biển vùng bờ tại các khu vực nghiên cứu.

Hàm lượng $\mathrm{NH}_{4}-\mathrm{N}$ trong môi trường nước biển ven bờ tại khu vực nghiên cứu cũng có sự dao động mạnh từ 220,1 đến $1325,1 \mu \mathrm{g} / \mathrm{L}$ với giá trị trung bình $( \pm \mathrm{SD})$ là $534,8 \pm 280,2$ $\mu \mathrm{g} / \mathrm{L}$. Hàm lượng $\mathrm{NH}_{4}-\mathrm{N}$ thể hiện xu hướng tương tự như Nitrate với sự giảm rõ rệt từ cửa sông ra môi trường nước biển ven bờ (ANOVA, $\mathrm{F}=23,814, \mathrm{p}<0,001)$, với giá trị trung bình tương ứng là $295,6 \pm 73,2 \mu \mathrm{g} / \mathrm{L}, 405,7 \pm 126,7 \mu \mathrm{g} / \mathrm{L}$ và $835,3 \pm 246,4 \mu \mathrm{g} / \mathrm{L}$ cho nước biển ven bờ, rừng ngập mặn và cửa sông. Hàm lượng $\mathrm{PO}_{4}-\mathrm{P}$ không có sự khác biệt quá lớn gữa các khu vực nghiên cứu với khoảng dao động từ 1,6 đến $44,1 \mu \mathrm{g} / \mathrm{L}$ và giá trị trung bình $( \pm \mathrm{SD})$ là $7,5 \pm 9,2 \mu \mathrm{g} / \mathrm{L}$. Một số điểm có giá trị $\mathrm{PO}_{4}$ cao hơn so với môi trường xung quanh nằm tại khu vực cửa sông và rừng ngập mặn, gần các cửa cống trao đổi nước của hoạt động NTTS trong đê. Kết quả nghiên cứu cũng cho thấy hàm lượng chất dinh dưỡng có sự dao động lớn trong môi trường nước tại khu vực cửa sông và mức độ dao động giảm dần tại khu vực rừng ngập mặn và nước biển ven bờ. Tuy nhiên, giá trị hàm lượng $\mathrm{NH}_{4}-\mathrm{N}$ và $\mathrm{NO}_{3}-\mathrm{N}$ trong khu vực có dấu hiệu tăng cao, với giá trị hàm lượng $\mathrm{NH}_{4}-\mathrm{N}$ đều vượt quá QCVN 10:2015 về nước biển ven bờ cho vùng nuôi trồng thủy sản và bảo tồn thủy sinh đối với nước biển ven bờ và rừng ngập mặn, còn tại khu vực cửa sông thì hàm lượng Amoni đã vượt quá giá trị giới hạn (GTGH) gây ô nhiễm môi trường nước. Đối với Nitrate trong nước biển ven bờ, trong QCVN 10-MT:2015/BTNMT không quy định hàm lượng Nitrate nhưng khi đối sánh với tiêu chuẩn môi trường ASEAN thì hàm lượng Nitrate đã vượt từ 2-8 lần so với GTGH $(60 \mu \mathrm{g} / \mathrm{L})[15]$. Mặc dù các loài sinh vật và hệ sinh thái có ngưỡng chịu đựng độc tính với hàm lượng các chất dinh dưỡng trong môi trường nước biển khá cao, sự gia tăng hàm lượng các chất dinh dưỡng cũng là vấn đề đáng quan tâm và xử lý trong thời gian tới [16-18]. Ngoài ra, thời điểm lấy mẫu nghiên cứu được thực hiện trong mùa khô với hàm lượng các chất dinh dưỡng tại các cửa sông miền Bắc có xu hướng thấp hơn so với mùa mưa [13-14], nên việc đánh giá tác động tích lũy và lâu dài của ô nhiễm các chất dinh dưỡng lên các loài sinh vật cũng rất cần thiết được thực hiện trong các nghiên cứu tiếp theo.

Kết quả đánh giá tương quan cho thấy giá trị hàm lượng các chất dinh dưỡng có tương quan nghịch ở mức trung bình đối với giá trị TDS và độ muối. Hàm lượng $\mathrm{PO}_{4}-\mathrm{P}$ có tương quan thuận ở mức trung bình đối với $\mathrm{NO}_{3}-\mathrm{N}_{\text {và }} \mathrm{NH}_{4}-\mathrm{N}$, trong đó $\mathrm{NO}_{3}-\mathrm{N}$ và $\mathrm{NH}_{4}-\mathrm{N}$ có tương quan thuận rất cao. Sự tương quan giữa $\mathrm{NO} 3-\mathrm{N}$ và $\mathrm{NH}_{4}-\mathrm{N}$ trong môi trường biển gắn liền với các nguồn phát sinh chất dinh dưỡng và quá trình địa hóa của Nitơ trong môi trường nước biển và cửa sông [19]. Đối với hàm lượng $\mathrm{PO}_{4}-\mathrm{P}$ có giá trị thấp trong môi trường biển nhưng sự tương quan thuận giữa $\mathrm{PO}_{4}-\mathrm{P}$ với $\mathrm{NO}_{3}-\mathrm{N}$ và $\mathrm{NH}_{4}-\mathrm{N}$ có thể liên quan đến nguồn gốc phát tán của các chất dinh dưỡng từ lục địa ra môi trường [20]. Như vậy xu hướng hàm lượng của 
các chất dinh dưỡng giảm dần từ khu vực cửa sông ra rừng ngập mặn và nước biển ven bờ. Xu hướng phân bố này phù hợp với quá trình pha loãng và hấp thụ chất ô nhiễm tại cửa sông và rừng ngập mặn trước khi được đưa ra môi trường nước biển ven bờ [21].

Bảng 2. So sánh hàm lượng các chất dinh dưỡng tại khu vực nghiên cứu với một số khu vực khác trong và ngoài nước.

\begin{tabular}{|c|c|c|c|c|c|}
\hline $\begin{array}{l}\text { Khu vực } \\
\text { nghiên cứu }\end{array}$ & $\begin{array}{c}\text { Môi } \\
\text { trường }\end{array}$ & $\mathbf{N H}_{4}-\mathbf{N}(\mu \mathrm{g} / \mathrm{L})$ & $\mathbf{N O}_{3}-\mathbf{N}(\mu \mathrm{g} / \mathrm{L})$ & $\mathbf{P O}_{4}-\mathbf{P}(\mu \mathrm{g} / \mathrm{L})$ & $\begin{array}{c}\text { Tài liệu } \\
\text { tham khảo }\end{array}$ \\
\hline \multirow{3}{*}{$\begin{array}{c}\text { Nam châu } \\
\text { thổ sông } \\
\text { Hồng }\end{array}$} & $\begin{array}{l}\text { Rừng ngập } \\
\text { măn }\end{array}$ & $405,7 \pm 126,7$ & $192,3 \pm 47,5$ & $8,2 \pm 7,9$ & \multirow{3}{*}{$\begin{array}{l}\text { Khu vực } \\
\text { nghiên cứu }\end{array}$} \\
\hline & Cửa sông & $835,3 \pm 246,4$ & $454,8 \pm 204,1$ & $8,9 \pm 12,6$ & \\
\hline & $\begin{array}{l}\text { Nước biền } \\
\text { ven bờ }\end{array}$ & $295,6 \pm 73,2$ & $119 \pm 50,7$ & $2,8 \pm 1,3$ & \\
\hline \multirow{2}{*}{$\begin{array}{l}\text { Vân Đồn } \\
\text { Hải Phòng }\end{array}$} & Lạch triều & $126,8-151,9$ & $80,9-86,5$ & $23,85-24,14$ & [14] \\
\hline & $\begin{array}{l}\text { Cửa sông } \\
\text { và nước } \\
\text { biển ven bờ }\end{array}$ & $16,5-571,5$ & $86,7-285,4$ & $8,81-39,0$ & [13] \\
\hline $\begin{array}{c}\text { Nha Trang } \\
\text { (2017) }\end{array}$ & $\begin{array}{l}\text { Nước biển } \\
\text { ven bờ }\end{array}$ & $21,15 \pm 17,42$ & $32 \pm 0,93$ & $7,64 \pm 4,57$ & [22] \\
\hline $\begin{array}{l}\text { Vũng Tàu } \\
\text { (2017) }\end{array}$ & $\begin{array}{c}\text { Nước biển } \\
\text { ven bờ }\end{array}$ & $16,10 \pm 5,71$ & $87 \pm 25$ & $13,47 \pm 2,87$ & [22] \\
\hline $\begin{array}{l}\text { Nam Du, } \\
\text { Kiên giang }\end{array}$ & Nước biển & $27-136$ & $16-42$ & $5-13$ & [23] \\
\hline Cần Giờ & Cửa sông & $150-300$ & $600-1500$ & $150-320$ & {$[24]$} \\
\hline $\begin{array}{c}\text { Phuket } \\
\text { (Thái Lan) } \\
\text { Vịnh }\end{array}$ & Biển ven bờ & $0-93,15$ & $0-41,3$ & $0-81,30$ & [25] \\
\hline $\begin{array}{c}\text { Panguil } \\
\text { (Phi-líp-pin) }\end{array}$ & Biển ven bờ & - & $300-900$ & $100-500$ & [26] \\
\hline $\begin{array}{c}\text { Merbok } \\
\text { (Malaysia) }\end{array}$ & Cửa sông & 100-1180 & $50-210$ & $60-80$ & [27] \\
\hline GTGH & & $\begin{array}{c}100^{*} \\
\text { (QCVN 10- } \\
\text { MT:2015/BTNMT) }\end{array}$ & $\begin{array}{c}60^{* *} \\
(\mathrm{ASEAN})\end{array}$ & $\begin{array}{c}200^{*} \\
\text { (QCVN 10- } \\
\text { MT:2015/BTNMT) }\end{array}$ & \\
\hline
\end{tabular}

* QCVN 10-MT:2015/BTNMT đối với nước biển ven bờ cho nuôi trồng thủy hải sản và bảo tồn thủy sinh

** Tiêu chuẩn môi trường ASEAN đối với nước biển ven bờ cho bảo tồn thủy sinh

Dựa trên các kết quả đã phân tích kể trên, môi trường nước biển tại khu vực nghiên cứu đã có xu hướng gia tăng hàm lượng các chất dinh dưỡng và cao hơn khá nhiều so với các khu vực khác trong và ngoài nước (Bảng 2). So sánh với khu vực ở miền Bắc Việt Nam, giá trị $\mathrm{NO}_{3}-\mathrm{N}$ và $\mathrm{NH}_{4}-\mathrm{N}$ tương đối cao so với các vùng biển và cửa sông khác như đảo Vân Đồn [14], cửa sông Cấm và Bạch Đằng [13], và tương đương với khu vực Cần Giờ, thành phố Hồ Chí Minh [24], Vịnh Paguil, Phi-líp-pin và cửa sông Merbok, Malaysia [26-27]. Giá trị hàm lượng $\mathrm{NO}_{3}-\mathrm{N}$ và $\mathrm{NH}_{4}-\mathrm{N}$ trong khu vực này cũng cao hơn rõ rệt so với các vùng biển ven bờ khác tại Việt Nam như Vũng Tàu, Nha Trang, Kiên Giang [22-23] hay Phuket (Thái Lan) [25]. Nguồn phát sinh của các chất dinh dưỡng này chủ yếu từ các hoạt động nhân sinh do con người gây ra như nông nghiệp, nuôi trồng thủy sản, công nghiệp, chất thải đô thị,... và một phần nhỏ do các quá trình tự nhiên như phân hủy vật chất hữu cơ và phát triển của vi sinh vật $[25,28]$. Do vậy, các cửa sông như tại khu vực nghiên cứu, khu vực cửa sông Bạch Đằng, khu vực Cần Giờ gần các khu đô thị và khu vực phát triển nông nghiệp thường thể hiện xu hướng có hàm lượng các chất dinh dưỡng cao hơn các vùng biển mở khác, đồng thời đã đạt tới ngưỡng GTGH của QCVN 10-MT:2015/BTNMT và tiêu chuẩn môi trường ASEAN.

Một trong những nguyên nhân có thể dẫn đến sự gia tăng hàm lượng các chất dinh dưỡng trong môi trường nước biển ven bờ khu vực nghiên cứu liên quan đến sự ô nhiễm môi trường tại lưu vực sông Nhuệ Đáy trong thời gian qua. Nguyên nhân của hiện tượng này do đầu 
nguồn của hệ thống sông này tiếp nhận trực tiếp phần lớn nước thải sinh hoạt và nước thải công nghiệp từ các đô thị, khu dân cư và các khu-cụm công nghiệp tại Hà Nội, Hà Nam, Ninh Bình, Nam Định [12]. Nhằm giảm thiểu hàm lượng các chất dinh dưỡng này trong môi trường nước biển và cửa sông cần có các giải pháp xử lý từ nguồn phát thải trong lục địa, xử lý nước thải NTTS tại các khu vực ven biển. Ngoài ra, việc tiếp tục trồng và bảo vệ rừng ngập mặn ven biển cũng là một giải pháp làm giảm tải lượng các chất dinh dưỡng thải ra môi trường biển do chức năng lọc các chất ô nhiê̂m và làm chậm quá trình phát tán các chất ô nhiễm của HST này tại khu vực cửa sông ven biển $[19,21]$. Trong nghiên cứu này, giá trị hàm lượng các chất dinh dưỡng thể hiện xu hướng giảm rõ rệt từ cửa sông tới rừng ngập mặn và nước biển ven bờ, thể hiện rừng ngập mặn trong khu vực này cũng có giá trị đổi với việc hấp thụ và giảm thiểu hàm lượng các chất dinh dưỡng trong môi trường. Để làm rõ được các quá trình kể trên, các nghiên cứu về biến đổi hàm lượng chất dinh dưỡng theo không gian và thời gian là rất cần thiết được thực hiện tại khu vực này trong thời gian tới.

\section{Kết luận}

Kết quả nghiên cứu cho thấy khu vực phía nam châu thổ sông Hồng tại thời điểm lấy mẫu đã có dấu hiệu gia tăng hàm lượng các chất dinh dưỡng (Amoni, Nitrate) trong nước biển ven bờ tại các khu vực rừng ngập mặn, cửa sông và nước biển ven bờ. Một số điểm tại khu vực này cho thấy giá trị hàm lượng các chất dinh dưỡng (Amoni, Nitrate) đã vượt quá GTGH trong QCVN 10-MT:2015/BTNMT và Tiêu chuẩn môi trường ASEAN. Tuy nhiên, hàm lượng các chất dinh dưỡng trong nước biển ven bờ tại các khu vực có rừng ngập mặn có giá trị thấp hơn rõ rệt so với khu vực cửa sông, thể hiện vai trò là "màng lọc tự nhiên" giúp lắng đọng và hấp thụ các chất ô nhiễm từ lục địa trước khi thải ra môi trường biển. Nhìn chung, khu vực vùng bờ phía nam Châu thồ sông Hồng đã bước đầu xảy ra hiện tượng gia tăng hàm lượng các chất dinh dưỡng trong môi trường nước biển ven bờ, nếu xảy ra trong thời gian dài sẽ dẫn đến nguy cơ phú dưỡng và tác động trực tiếp đến hệ sinh thái rừng ngập mặn, vùng nước cửa sông và các hệ sinh thái đất ngập nước khác trong khu vực. Vì vậy, các nghiên cứu có tính liên tục theo không gian và thời gian là rất cần thiết được thực hiện trong thời gian tới để làm rõ sự biến động theo không gian và thời gian của hàm lượng các chất dinh dưỡng trong môi trường nước biển ven bờ.

Đóng góp của tác giả: Xây dựng ý tưởng nghiên cứu: L.V.D., P.V.H.; Lựa chọn phương pháp nghiên cứu: L.V.D., N.T.T.; Xử lý số liệu: L.V.D., N.T.T.; Phân tích mẫu: L.V.D., N.D.K., L.V.D.; Lấy mẫu: L.V.D., P.V.H., N.D.K., L.V.D.; Viết bản thảo bài báo: L.V.D., P.V.H.; Chỉnh sửa bài báo: L.V.D., N.T.T., P.V.H.

Lời cảm ơn: Nghiên cứu này được thực hiện dưới sự tài trợ của đề tài nghiên cứu khoa học cấp Đại học Quốc gia Hà Nội, mã số QG19.01. Bên cạnh đó, tập thể tác giả trân trọng cảm ơn sự giúp đỡ của các cơ quan địa phương trong quá trình khảo sát và thực hiện nghiên cứu này.

Lời cam đoan: Tập thể tác giả cam đoan bài báo này là công trình nghiên cứu của tập thể tác giả, chưa được công bố ở đâu, không được sao chép từ những nghiên cứu trước đây; không có sự tranh chấp lợi ích trong nhóm tác giả.

\section{Tài liệu tham khảo}

1. Tạng, V.T. Sinh thái học các hệ cửa sông Việt Nam (khai thác, duy trì và quản lý tài nguyên cho phát triển bền vững). 2009.

2. Barcellos, D. Phosphorus enriched effluents increase eutrophication risks for mangrove systems in northeastern Brazil. Mar. Pollut. Bull. 2019, 142, 58-63.

3. Fauzi, A. Shrimp pond effluent dominates foliar nitrogen in disturbed mangroves as mapped using hyperspectral imagery. Mar. Pollut. Bull. 2013, 76(1), 42-51. 
4. Fauzi, A. Eutrophication of mangroves linked to depletion of foliar and soil base cations. Environ. Monit. Assess. 2014, 186(12), 8487-8498.

5. Manna, S. Dynamics of Sundarban estuarine ecosystem: eutrophication induced threat to mangroves. Saline Systems, 2010, 6(1), 8.

6. Mukhopadhyay, S. Fluxes of nutrients from the tropical River Hooghly at the landocean boundary of Sundarbans, NE Coast of Bay of Bengal, India. J. Mar. Syst. 2006, 62(1-2), 9-21.

7. Dangremond, E.M. Nitrogen Enrichment Accelerates Mangrove Range Expansion in the Temperate-Tropical Ecotone. Ecosystems 2020, 23, 703-714.

8. Hayes, M.A. The contrasting effects of nutrient enrichment on growth, biomass allocation and decomposition of plant tissue in coastal wetlands. Plant Soil 2017, 416(1), 193-204.

9. Luu, T.N.M. N, P, Si budgets for the Red River Delta (northern Vietnam): how the delta affects river nutrient delivery to the sea. Biogeochemistry 2012, 107(1), 241259.

10. Le, T.P.Q. Long-term biogeochemical functioning of the Red River (Vietnam): past and present situations. Reg. Environ. Change 2015, 15(2), 329-339.

11. Skalar Analytical BV. Skalar SAN++ user guide. Breda, The Netherlands, 2019.

12. Bộ Tài nguyên và Môi trường. Báo cáo hiện trạng môi trường quốc gia năm 2018: Môi trường nước lưu vực sông, 2018.

13. Trang, C.T.T. Water quality in Cam-Bach Dang estuary area. In IRD Symposium on marine science, Hai Phong, 2013.

14. Tran, T.T.T. Nghiên cứu, xác định một số yếu tố dinh dưỡng môi trường nước nơi Ngán cư trú ở ven bờ biển Tỉnh Quảng Ninh. VNU J. Sci. Earth Environ. Sci. 2017, 33(1), 82-89.

15. Secretariat, A. ASEAN Marine Water Quality Management Guidelines and Monitoring Manual, in Australia Marine Science and Technology Ltd. (AMSAT), Australia, 2008.

16. Randall, D.J.; Tsui, T.K.N. Ammonia toxicity in fish. Mar. Pollut. Bull. 2002, 45(1), 17-23.

17. Jensen, F.B. Nitrite disrupts multiple physiological functions in aquatic animals. Comp. Biochem. Physiol. A: Mol. Integr. Physiol. 2003, 135(1), 9-24.

18. Eddy, F.B. Ammonia in estuaries and effects on fish. J. Fish Biol. 2005, 67(6), 14951513.

19. Tanaka, K.; Choo, P.S. Influences of nutrient outwelling from the mangrove swamp on the distribution of phytoplankton in the Matang Mangrove Estuary, Malaysia. $J$. Oceanogr. 2000, 56(1), 69-78.

20. Gurmeet Singh, R.C.; Rajesh, K.R.; Prasad, M.B.; Ramanathan, A.L. Phosphorus dynamics in mangroves of India. Curr. Sci. 2015, 108(10), 1874-1881.

21. Lin, B.B.; Dushoff, J. Mangrove filtration of anthropogenic nutrients in the Rio Coco Solo, Panama. Manage. Environ. Qual. Int. J. 2004, 15(2), 131-142.

22. Tâm, P.H. Chất lượng nước biển ven bờ từ dữ liệu các trạm quan trắc môi trường phía Nam Việt Nam (2013-2017). Tạp chi Khoa hoc ĐHQGHN: Các Khoa học Trái đất và Môi trường 2018, 34, 95-109.

23. Lưu, N.T.; Đỗ, A.D.; Nguyễn, C.T. Hiện trạng môi trường nước, trầm tích quần đảo Nam Du, Kiên Giang, Việt Nam. Tạp chi Khoa học Truờng Đại học Cần Tho 2021, 57(2), 21-27.

24. Pham, T.L. Environmental gradients regulate the spatio-temporal variability of phytoplankton assemblages in the Can Gio Mangrove Biosphere Reserve, Vietnam. Ocean Sci. J. 2017, 52(4), 537-547. 
25. Reopanichkul, P. Wastewater discharge degrades coastal waters and reef communities in southern Thailand. Mar. Environ. Res. 2010, 69(5), 287-296.

26. Canini, N.D.; Metillo, E.B.; Azanza, R.V. Monsoon-influenced phytoplankton community structure in a Philippine mangrove estuary. Trop. Ecol. 2013, 54(3), 331343.

27. Fatema, K.; Maznah, W.W.; Isa, M.M. Spatial and temporal variation of physicochemical parameters in the Merbok Estuary, Kedah, Malaysia. Trop. Life Sci. Res. 2014, 25(2), 1.

28. Downing, J.A.; McClain, M.; Twilley, R.; Melack, J.M.; Elser, J. The impact of accelerating land-use change on the $\mathrm{N}-$ Cycle of tropical aquatic ecosystems: Current conditions and projected changes. Biogeochemistry 1999, 46, 109-148.

\title{
Characteristics of selected nutrients in coastal waters from the southern Red River Delta
}

\author{
Luu Viet Dung, ${ }^{1, *}$, Nguyen Tai Tue ${ }^{2,1}$, Pham Van Hieu ${ }^{3}$, Nguyen Doanh Khoa ${ }^{1}$, Le Van \\ Dung ${ }^{1}$ \\ ${ }^{1}$ Key Laboratory of Geoenvironment and Climate Change Response, VNU University of \\ Science, Vietnam National University, Hanoi, Vietnam; dungluuviet@gmail.com; \\ tuenguyentai@hus.edu.vn; khoa.k59ktdc@gmail.com; \\ levandung.qltnmtkhtn@gmail.com \\ ${ }^{2}$ Faculty of Geology, VNU University of Science, Vietnam National University, Hanoi, \\ Vietnam; dungluuviet@gmail.com; tuenguyentai@hus.edu.vn; \\ khoa.k59ktdc@gmail.com; levandung.qltnmtkhtn@gmail.com \\ ${ }^{3}$ Vietnam Institute of Sea and Islands, Vietnam Administration of Sea and Islands; \\ hieupv.env@gmail.com
}

\begin{abstract}
Nutrients in coastal waters play essential roles for coastal ecosystems and organisms, but the increasing concentration of these nutrients also negatively impacts the environment. The present study collected and analyzed the content of nutrients, including Ammonium, Nitrate, Phosphate, and physicochemical parameters of coastal waters from the southern Red River Delta. Results showed that the concentration of Nitrate significantly decreased from estuaries, mangroves to nearshore waters with an average of $454.8 \pm 204.1$ $\mu \mathrm{g} / \mathrm{L}, 192.3 \pm 47.5 \mu \mathrm{g} / \mathrm{L}$ to $119 \pm 50.7 \mu \mathrm{g} / \mathrm{L}$, respectively. Similar results were observed for Ammonium concentrations with an average value of $295.6 \pm 73.2 \mu \mathrm{g} / \mathrm{L}, 405.7 \pm 126.7 \mu \mathrm{g} / \mathrm{L}$, to $835.3 \pm 246.4 \mu \mathrm{g} / \mathrm{L}$, for nearshore waters, mangroves, and estuaries, respectively. According to Vietnam (QCVN 10-MT:2015/BTNMT) and ASEAN environmental standards for coastal marine environments, the concentration of Ammonium and Nitrate has exceeded the allowable limit. The study also points to the role of mangroves in absorbing nutrients transported from the mainland to the coastal area and further investigation is necessary to clarify this process in the coastal area.
\end{abstract}

Keywords: Mangroves; Estuary; Coastal zone; Nutrients; Red River Delta. 